\title{
ISOLATION AND GROWTH CHARACTERIZATION OF CHLORATE AND/OR BROMATE RESISTANT MUTANTS GENERATED BY SPONTANEOUS AND INDUCED FOREWORD MUTATIONS AT SEVERAL GENE LOCI IN ASPERGILLUS NIGER
}

\author{
Ghassan J. M. Kanan*, Heyam E. Al-Najjar \\ Department of Biological Sciences, Mu’tah University, Karak - Jordan, P. O. Box (7) \\ Submitted: April 25, 2009; Returned to authors for corrections: March 18, 2010; Approved: June 21, 2010.
}

\begin{abstract}
We aimed her mainly to evaluate the contribution of newly employed bromate selection system, in obtaining new Aspergillus niger nitrate/nitrite assimilation defective mutants, through Ultraviolet treatment (UV), 1, 2, 7, 8-Diepoxyoctane (DEO), phenols mixture (Phx)) and spontaneous treatments. The newly employed bromate selection system was able to specify only two putative novel mutant types designated brn (bromate resistant but chlorate sensitive (RS) strain, which may specify nitrite specific transporter) and cbrn mutants (bromate resistant and chlorate resistant strain, which may specify nitrate/nitrite bispecific system). The most relevant and innovative findings of this research work involve the isolation of the RR (cbrn) mutants (a new type of nitrate assimilation defective mutants), that could be useful for studying the bispecific nitrate /nitrite transporter system. The majority of obtained bromate resistant mutants $(93.3 \%$ of the total mutants obtained by all treatments) were of the brn type, whereas the remaining percentage (6.76\%) was given to $c b r n$ strains. The highest percentages of brn mutant strains ( $48 \%$ and $58.6 \%$ of the total RS strains) were obtained with UA after spontaneous and Phx treatment, whereas Trp has generated $29 \%$ and $42 \%$ of RS strains after UV and DEO treatments, respectively. The obtained ratios of cbrn mutants were higher (i.e. in the range of $8.4 \%-11.64 \%$ of the total bromate mutants) with chemical treatments, especially when U.A or Pro was serving as sole $N$-sources at $25^{\circ} \mathrm{C}$ rather than $37^{\circ} \mathrm{C}$. A $69 \%$ mutants` yield of Aspergillus niger mutant strains representing nine gene loci (niaD, cnx-6 loci, nrt and nirA) were selected on the bases of chlorate $(600 \mathrm{mM})$ toxicity. All chlorate resistant mutants were completely sensitive to bromate $(250 \mathrm{mM})$. The niaD mutants showed the highest percentage $(73.97 \%)$ of chlorate resistant mutants obtained with all tested treatments. The UV treatment has generated the highest ratio $(86.9 \%)$ of niaD mutants, whereas, the least $(61 \%)$ was obtained with Phx treatment. The highest percentage of $c n x$ mutants (32\%) was obtained with Phx treatment. The DEO treatment as compared to other tested treatments was the best to use for obtaining the highest ratios of either $n r t(13.8 \%)$ mutants or nirA $(1.9 \%)$ mutants.
\end{abstract}

Key words: Aspergillus niger. chlorate. bromate. mutagenesis

*Corresponding Author. Mailing address: Dept of Biological Sciences; Mu'tah University Karak - Jordan; P. O. Box (7).; Tel: +962-032372380 Ext: 4223 Fax: +962-32375540 Mobile: 0795585053.; E-mail: gkanan@ mutah.edu.jo 


\section{INTRODUCTION}

The black mould Aspergillus niger has been subjected to various research and industrial uses for several decades since 1919, where its utility comes from strains ability to produce high levels of enzymes $(8,33)$. However, many mutant strains deficient in nitrate assimilation were isolated on the bases of chlorate toxicity through spontaneous and induced mutagenesis $(5,13,16)$. Six phenotypic classes of chlorate resistant mutants (nrtA, niiA, niaD, cnx, nirA and areA) were characterized and designated as in Aspergillus nidulans (9, 13, 20). Genetic studies revealed that niaD and niiA genes are the structural gene for nitrate and nitrite reductase enzymes respectively, (11, 31). The transcription of both genes depends on two positively acting transcription factors, one is encoded by the nirA gene, (mediates nitrate and nitrite induction) and required for efficient transcription of niaD, niiA, and nrtA $(6,27)$. The second protein is encoded by the areA gene, mediates nitrogen metabolite repression, and is a general transcription factor needed for the efficient transcription of many genes involved in the utilization of different nitrogen sources $(12,20,21)$. The cnx genes of $A$. niger and A. nidulans were found to be required for the biosynthesis of molybdenum cofactor, needed for the activity of both molybdoenzymes $(4,13,32)$. Potassium bromate has been classified as a genotoxic carcinogen that induces DNA damage to prokaryotic and eukaryotic mutational test systems $(3,14)$. In addition, potassium bromate has caused kidney tumor to rodents $(23,36)$. However, due to its toxilogical effects, there have been a lot of controversies in the use of potassium bromate as a food and beverages additive or as flour improver (24). However, it has been employed here as a new selection system for the isolation of new A. niger nitrate assimilation defective mutants. The mutagen 1, 2, 7, 8Diepoxyoctane (DEO) is one of the most potent mutagens in a wide variety of mutational test systems, including Salmonella typhimurium (25), Saccharomyces cerevisia (26), A. nidulans (17), and human epithelial cells (34). In addition, Ultraviolet light (UV) has widely been used as a mutagen, where it was able to produce different mutant types in $A$. niger and $A$. nidulans $(13,17,20)$. However, the phenols Mixture (Phx) which is usually used as a standard solution for water pollution analysis, was reported as a mutagen and a carcinogenic agent, as listed by US Environmental Protection Agency (EPA) (29). To the best of our knowledge no previous mutagenic research methods were conducted for mutants selection (whether in prokaryotic or eukaryotic mutational test systems), using bromate, in addition to the traditional chlorate resistance selection system. Thus, we aimed here mainly to explore the contribution of newly employed bromate selection system for obtaining new Aspergillus niger nitrate/nitrite assimilation defective mutants, that might be useful for studying the existence of a bispecific nitrate /nitrite transporter system at the gene level. Furthermore, the current study aimed for elucidating the influence of mutagenic treatments employed (DEO, Phx, Ultraviolet and spontaneous treatment), the ten tested nitrogen sources and the selection temperatures $\left(25^{\circ} \mathrm{C}\right.$ and $37^{\circ} \mathrm{C}$ ), on the nature of mutants obtained and on mutant yield.

\section{MATERIALS AND METHODS}

\section{Wild-Type Fungal Strain and Media}

The wild-type strain (with regard to nitrogen regulation) used for mutants isolation was [IMI60286 (ATCC 10864)]. Gene symbols are those in standard use (7). Standard Aspergillus nidulans growth media and handling techniques were as described by Clutterbuck (7).

\section{Potassium Bromate and Chlorate Toxicity to A. niger Wild-}

\section{Type Strain}

Bromate toxicity $(50,100,150,200,250,300,350,400$ and $500 \mathrm{mM}$ ) to wild-type strain was investigated by plating conidiospores suspension (approximately $1 \times 10^{8}$ conidiospores $/ \mathrm{mL}$ ) on glucose supplemented minimal medium, containing a sole $N$-source and a definite bromate concentration as stated above. Similarly, different concentrations of potassium chlorate $(100,200,300,400,500$, 600,700 and $800 \mathrm{mM}$ ) were also investigated. 
Isolation of $A$. niger Bromate and/or Chlorate Resistant Mutants by Spontaneous and Induced Mutagenesis

Spontaneous Treatment: Mutant strains were isolated on the basis of chlorate $(600 \mathrm{mM})$ and/or bromate $(250 \mathrm{mM})$ resistance with a sole source of nitrogen as described previously (9). Ten nitrogen sources were used and these include: uric acid (UA), proline (Pro), glutamic acid (Glu), histidine (His), aspartic acid (Asp), arginine (Arg), tyrosine (Tyr), tryptophan (Trp), lysine (Lys) and cystine (Cys). Conidiospores were suspended in $5 \mathrm{~mL}$ normal saline-Tween $80(0.05 \%)$, then adjusted to a concentration of $1 \times 10^{8}$ conidiospores $/ \mathrm{mL}$. The $5 \mathrm{~mL}$ suspension was added to $20 \mathrm{~mL}$ of $0.1 \mathrm{M}$ potassium orthophosphate buffer $(\mathrm{pH}$ 5.8) and incubated at room temperature for $40 \mathrm{~min}$. Conidia were pelleted, washed twice with sterile distilled water and resuspended in sufficient volume of saline-Tween 80 solution. The suspension was divided into aliquots of $200 \mu \mathrm{L}$ each, then plated on glucose supplemented minimal medium containing chlorate $(600 \mathrm{mM})$ or bromate $(250 \mathrm{mM})$, a sole $N$-source $(10$ $\mathrm{mM})$ and sodium deoxycholate $(0.08 \%)$ for colony size restriction (22). Cultured plates were incubated at either $25^{\circ} \mathrm{C}$ or $37^{\circ} \mathrm{C}$.

\section{Mutagenesis with 1,2,7,8-Diepoxyoctan (DEO):}

Mutagenesis with Diepoxyoctane was performed as described previously $(1,2)$ by adding $5 \mathrm{~mL}$ conidia (approximately $1 \times 10^{8}$ conidiospores $/ \mathrm{mL}$ ) to $20 \mathrm{~mL}$ of $0.1 \mathrm{M}$ potassium orthophosphate buffer ( $\mathrm{pH} 5.8$ ) containing $12 \mathrm{mg} / \mathrm{mL}$ 1,2,7,8Diepoxyoctane (Aldrich chemical company). Treatment was for $40 \mathrm{~min}$ at $37^{\circ} \mathrm{C}$. Conidia were pelleted $(4233 \mathrm{R}$ Refrigerated Centrifuge) at $6000 \mathrm{rpm}$ for $10 \mathrm{~min}$, washed thrice with sterile distilled water and resuspended in sufficient volume of saline-Tween 80 solution. conidiospores were plated on selective madia and incubated as mentioned above.

Mutagenesis with Phenols Mixture (Phx): Mutagenesis with Phx mixture was performed as described above for DEO treatment, except that $12 \mathrm{mg} / \mathrm{mL}$ of phenols mixture were added to the conidiospores suspension. The tested Phx mixture was having the following constituents: 2,4-dinitrophenol, phenol, 4-nitrophenol, 2-chlorophenol, 2-methyl-4,6- dinitrophenol, 2-nitrophenol, 2,4-dimethylphenol, 4-chloro-3methylphenol, 2,4-dichlorophenol, 2,4,6-trichlorophenol, and pentachlorophenol (29).

Mutagenesis with Ultraviolet Light (UV): A $25 \mathrm{~mL}$ conidiospores suspension (approximately $1 \times 10^{8}$ conidiospores $/ \mathrm{mL}$ ) prepared in orthophosphate buffer as mentioned above, was irradiated with ultraviolet light (UV) at an intensity of 20 $\mathrm{J} / \mathrm{m}^{2} / \mathrm{s}$ (UV-lamp UVKL-6U; $254 \mathrm{~nm}$; Vetter GMBH, Wiesloch, Germany) for $40 \mathrm{~min}$ at room temperature. After irradiation conidiospores were processed by plating onto selective media as described for the spontaneous treatment.

\section{Selection of Bromate and/or Chlorate Resistant Mutants}

For confirmation of mutants obtained, the putative mutant strains grown on selective media post mutagenesis were further tested at both selection temperatures, on chlorate $(600 \mathrm{mM})$ and bromate $(250 \mathrm{mM})$ with a sole source of nitrogen $(10 \mathrm{mM})$. Assignment of mutations to their gene loci was carried out according to the criteria described previously by Cove (9) and Kanan (17). The assignment of mutations involved replica plating of mutant strains onto the following media types: (i) potassium bromate $(250 \mathrm{mM})$ with uric acid $(5 \mathrm{mM})$ as the best serving sole nitrogen source, (ii) potassium chlorate $(600 \mathrm{mM})$ with proline $(10 \mathrm{mM})$ as a sole nitrogen source, (iii) potassium nitrate $(10 \mathrm{mM})$, (iv) potassium nitrite $(5 \mathrm{mM})$, (v) hypoxanthine $(5 \mathrm{mM})$.

\section{Statistical Analysis}

One way ANOVA was carried out to determine the significant effect of tested $N$-sources and selection temperatures on mutants yield. This was followed by independent samples T-test and Post Hoc (Tukey) multiple comparison, to determine the level of significance for tested $\mathrm{N}$ sources, selection temperatures and their interactions, on ratios of generated mutants in different gene loci. Multivariate ANOVA and ANCOVA tests, using the SPSS program devised for Windows (version 10) were also used to determine the significant effect of applied treatments and other sources of variance. 


\section{RESULTS}

Potassium Bromate and Chlorate Toxicity to A. niger WildType Strain

Results obtained indicate that bromate and chlorate toxicity to $A$. niger wild-type strain were achieved at a concentration of $250 \mathrm{mM}$ and $600 \mathrm{mM}$ respectively, where complete inhibition of fungal growth was reached.

\section{Conidiospores Viability Assays After Mutagenic \\ Treatments}

Viability tests were performed concurrently with mutagenic treatments and the estimated viabilities in term of survivals/mL for spontaneous, DEO, Phx and UV treatments were $8.0 \times 10^{4}, 1.5 \times 10^{5}, 2.8 \times 10^{5}$ and $3.3 \times 10,,^{5}$ respectively. However, the percentages of survivals after indicated treatments have reached approximately 100\%, 35.4\%, 50.32\% and $56.63 \%$, respectively.

\section{Effect of Treatments on Proportions of Chlorate Resistant}

\section{Mutant Classes}

Results presented in Table 1 indicate that a sum of 6139 nitrate assimilation defective mutant strains (i.e. $68.98 \%$ mutants`yield) in nine different loci (niaD, cnx-6 loci, nrt and nirA genes) were isolated on the bases of chlorate $(600 \mathrm{mM})$ toxicity using four mutagenic treatments. However, the obtained mutants`yield (expressed as percentages) after spontaneous, DEO, Phx and UV treatments, were 47.9\%; 90\%; $68 \%$; and $93.4 \%$, respectively (Table 1). These mutants were chlorate resistant $(600 \mathrm{mM})$ but bromate $(250 \mathrm{mM})$ sensitive strains (designated SR-type). The chlorate resistant mutant strains were selected at two temperature regimes $\left(25^{\circ} \mathrm{C}\right.$ and $37^{\circ}$ C). However, results of $\mathrm{T}$-test indicate that the selection temperature has not significantly influenced the ratios of generated mutants with either spontaneous treatment $(P$ values ranged from $0.761-0.942)$ or UV treatment $(P$ values ranged from $0.226-0.398)$. The selection at these temperatures $\left(25^{\circ} \mathrm{C}\right.$ and $37^{\circ} \mathrm{C}$ ) did not significantly influence the ratios of generated mutants when Arg, His, Pro, Glu, Asp and Tyr were used as sole $N$-sources with all treatments, where approximately equal ratios of mutants have been obtained at both temperatures. The above mentioned amino acids (except Tyr) were serving as the best sole sources of nitrogen (generated the highest mutants`yield) for mutants selection with all treatments employed (Table 1). The proportions of confirmed mutant classes (at several gene loci) obtained with these amino acids have ranged from $14.5 \%$ to $17.4 \% ; 12.9 \%$ to $20.3 \% ; 15.6 \%$ to $23.4 \%$ and $19.5 \%$ to $23.4 \%$ when spontaneous, DEO, Phx and UV treatments, respectively were employed. The amino acids Lys and Trp did not effectively serve as sole sources of nitrogen for mutants selection at $25^{\circ} \mathrm{C}$ with all treatments employed (except DEO treatment where, approximately equal ratios of mutants were achieved at both selection temperatures), where no single mutant was selected under these conditions. In contrast, when selection was performed at $37^{\circ} \mathrm{C}$ with the four mutagenic treatments the same amino acids (Lys and Trp) have generated mutants`yield in the range of $2.9 \%-7.8 \%$ and $3.9 \%-17.4 \%$, respectively (Table 1). Uric acid was not serving as a sole $N$-source for mutants selection at $37^{\circ} \mathrm{C}$ with all treatments (except with DEO treatment; equal ratios were obtained at both $25^{\circ} \mathrm{C}$ and $37^{\circ} \mathrm{C}$ ), where no single mutant was obtained at this temperature. Furthermore, the amino acid Cys was not the $\mathrm{N}$ source of choice for mutants selection at either $25^{\circ} \mathrm{C}$ and $37^{\circ}$ $\mathrm{C}$, where no single mutant was obtained with all treatments employed (except with DEO treatment; mutants were obtained in $1: 2$ ratio at $25^{\circ} \mathrm{C}$ and $37^{\circ} \mathrm{C}$, respectively). Results of Multivariate ANCOVA indicate that the DEO treatment as compared to spontaneous treatment has significantly influenced the ratios of generated mutant types (except niaD mutants ( $F$ value $=1.84)) . \quad$ The calculated $F$ values $(149.19,136.7$ and 49.53) for cnx, nrt and nirA mutants, respectively were higher than the critical $F$ value (4.046) at $d f 1$ and $d f 49$. Furthermore, the ratios of generated mutants (except for $n r t$ mutants; $F$ value $=2.05$ ) were significantly influenced by the Phx mutagenic treatment. The calculated $F$ values (49.63, 42.70 and 35.86) for ratios of niaD, nirA and cnx mutants, respectively were higher than the tabulated $F$ value (4.07) at $d f 1$ and $d f 49$. The 
UV treatment had significantly influenced the ratios of niaD, cnx and nirA mutants (but not that of nrt mutants), where the calculated $F$ values for these mutants (185.05, 126.95 and 36.17 respectively), were higher than the tabulated $F$ value (4.07) at $d f 1$ and $d f 44$. Results of one way ANOVA indicate that the used $N$-source with all mutagenic treatments had significantly $(P$ values ranged from $0.001-0.026)$ influenced the ratios of obtained mutants in the investigated gene loci (niaD, cnx , nrt ) except nirA gene ( $P$ values ranged from 0.098 0.165). The niaD mutants as compared to other mutant classes have represented the highest percentage $(73.97 \%$ of total mutants) of mutants yield obtained with all treatments. The obtained yields of niaD mutants were $86.9 \% ; 72.5 \% ; 71.2 \%$ and $61 \%$ with UV, spontaneous, DEO and $\mathrm{Phx}$ treatment, respectively. Presented results (Table 1) indicate that the amino acid Lys was serving as the best sole source of nitrogen for obtaining niaD mutants with all mutagenic treatments (except for Pro where, a 93\% mutants`yield was obtained with UV treatment), where a percentage of $84 \%$ to $90 \%$ of the total confirmed mutants was achieved with Lys. However, these percentages of mutants have reflected $3.4 \%$ to $17.5 \%$ of the total niaD mutants produced under indicated conditions. Furthermore, results of Post Hoc (Tukey) multiple comparisons indicate that all $N$-sources (except Cys and UA) which were used with the spontaneous treatment had significantly $(P<0.05)$ influenced the ratios of generated niaD mutants. The highest percentage of niaD mutants $(84 \%$ of the total confirmed mutants) was obtained with Lys while the least (69\%) was generated with Pro. In addition, there were significant differences ( $P$ values ranged from 0.011-0.033) in niaD ratios obtained with His and those obtained with UA, Trp and Tyr after Phx treatment, where the highest percentage of mutants yield $(61 \%)$ was obtained with His. Moreover, there were significant differences ( $P$ values ranged from $0.014-0.045)$ in niaD mutants obtained with Pro (comprising 93\%) and ratios generated with UA, Trp or Tyr after UV treatment. The use of Arg, Glu and Pro as sole sources of nitrogen with DEO treatment did not reflect significant difference in obtained ratios of niaD muants ( $P$ values ranged from $0.997-1.000$ ).
The obtained cnx mutants were ranked the second in terms of mutants yield proportion $(17.80 \%)$, with all treatments (except DEO treatment). The percentages of cnx mutants`yield from the total confirmed mutant classes have reached $32 \% ; 21.7 \%$; $10.8 \%$ and $9 \%$ with Phx, spontaneous, DEO and UV treatment, respectively. The tested $N$-sources with spontaneous treatment (except Cys) showed no significant differences $(P<0.05)$ in ratios of cnx and nirA mutants which were isolated with the least percentage (Table 1). The amino acid Trp was serving as the best $N$-source for obtaining cnx mutants with spontaneous and UV treatments where, the mutants yield has reached $32 \%$ and $20 \%$ of the total confirmed mutant classes, respectively. However, this reflects $8.5 \%$ and $12.6 \%$ of the total cnx mutants produced under the indicated conditions. Furthermore, UA and Arg have generated $28 \%$ and $41 \%$ cnx mutants' yield with DEO and Phx treatments, respectively. This reflects $9.6 \%$ and $19.9 \%$ of the total cnx mutants generated by the indicated treatments (Table 1). There were significant differences $(P$ values ranged from $0.020-0.043$ ) in $\operatorname{cnx}$ ratios obtained with either Pro or Asp after DEO treatment and that obtained with Lys or Tyr (Table 1), where the highest percentage (12.9\%$16.6 \%$ ) was obtained with the former amino acid. However, the tested $N$-sources with the UV treatment have not reflected significant differences in ratios of $c n x$ and $n r t$ mutants. The $n r t$ mutants were ranked the third in terms of mutants yield $(6.4 \%)$ from the total confirmed mutants with all treatments (except DEO treatment; ranked the second $(13.76 \%)$ ), where a range from $4 \%$ (with either Phx or UV treatment) to $4.6 \%$ (with spontaneous treatment) was reached (Table 1). The highest percentages of $n r t$ mutants were achieved with Arg and His in all treatments (except DEO treatment; Cys has generated a $21 \%$ yield), where a range of mutants`yield from $5 \%$ to $8 \%$ of the total mutant classes was achieved (Table 1). Moreover, the used $N$-sources with spontaneous treatment had reflected significant differences in ratios of $n r t$ mutants $(P<0.05)$ where, the obtained highest percentage (i.e. in the range of $6.8 \%-8 \%$ ) was related to the influence of either Arg or His. There were significant differences ( $P$ values have ranged from 0.001 0.038) in ratios of $n r t$ mutants obtained with Arg after DEO 
treatment and those obtained with the rest of tested $\mathrm{N}$-sources, where the highest proportion from the total confirmed mutants was generated with Arg. In contrast, nirA mutants`yield was found to be the least obtained $(1.9 \%)$ with all tested treatments, where a range from $0.0 \%$ (with $\mathrm{UV}$ treatment) to $4.4 \%$ (with DEO treatment) mutants` yield from the total confirmed mutants generated by the specified treatment was achieved (Table 1).
There were siginificant differences $(P$ values in the range of 0.006 0.034) in ratios of $n r t$ mutants and nirA mutants obtained with Arg and those obtained with Lys, UA, Trp and Tyr after Phx treatment. The former amino acid has participated in the generation of the highest mutants` yield for $n r t$ mutants $(6.5 \%)$ and nirA mutants $(3.5 \%)$, while the latter amino acids have generated the least percentages (Table 1).

Table 1. Numbers and percentages of confirmed chlorate $(600 \mathrm{mM})$ resistant Aspergillus niger mutant classes generated after spontaneous and induced mutagenic treatments.

\begin{tabular}{|c|c|c|c|c|c|c|c|c|c|c|}
\hline \multirow[t]{3}{*}{ N-source ${ }^{a}$} & \multicolumn{10}{|c|}{ Spontaneous Treatment } \\
\hline & \multicolumn{2}{|c|}{ Confirmed mutant classes } & \multicolumn{2}{|c|}{ niaD mutants } & \multicolumn{2}{|c|}{ cnx mutants } & \multicolumn{2}{|c|}{ nrt mutants } & \multicolumn{2}{|c|}{ nirA mutants } \\
\hline & No & $\%$ & No & $\%$ & No & $\%$ & $\mathbf{N}$ & $\%$ & & $\%$ \\
\hline Arg & 300 & 17.4 & 216 & 72 & 57 & 19 & 24 & 8 & 3 & 1 \\
\hline His & 250 & 14.5 & 193 & 77 & 35 & 14 & 17 & 6.8 & 5 & 2 \\
\hline Lys & 50 & 2.9 & 42 & 84 & 6 & 12 & 2 & 4 & - & - \\
\hline Pro & 250 & 14.5 & 172 & 69 & 65 & 26 & 10 & 4 & 3 & 1 \\
\hline U.A & 50 & 2.9 & 34 & 68 & 15 & 30 & 1 & 2 & - & - \\
\hline Glu & 300 & 17.4 & 231 & 77 & 51 & 17 & 12 & 4 & 6 & 2 \\
\hline Asp & 300 & 17.4 & 210 & 70 & 81 & 27 & 6 & 2 & 3 & 1 \\
\hline Trp & 100 & 5.8 & 64 & 64 & 32 & 32 & 4 & 4 & - & - \\
\hline Tyr & 125 & 7.2 & 88 & 71 & 33 & 26 & 4 & 3 & - & - \\
\hline Cys & - & - & - & - & - & - & - & - & - & - \\
\hline Total No of mutants & 1725 & & 1250 & & 375 & & 80 & & 20 & \\
\hline \multirow[t]{3}{*}{ N-source } & \multicolumn{10}{|c|}{ DEO Treatment } \\
\hline & \multicolumn{2}{|c|}{ Confirmed mutant classes } & \multicolumn{2}{|c|}{ No of niaD } & \multicolumn{2}{|c|}{ No of $\operatorname{cnx}$} & \multicolumn{2}{|c|}{ No of $n r t$} & \multicolumn{2}{|c|}{ No of nirA } \\
\hline & No & $\%$ & No & $\%$ & No & $\%$ & No & $\%$ & No & $\%$ \\
\hline Arg & 275 & 20.3 & 180 & 65.5 & 15 & 5.5 & 50 & 18 & 5 & 1.8 \\
\hline His & 125 & 9.2 & 78 & 62 & 14 & 11 & 25 & 20 & 8 & 6.4 \\
\hline Lys & 50 & 3.7 & 42 & 84 & 3 & 6 & 5 & 10 & - & - \\
\hline Pro & 225 & 16.6 & 165 & 73 & 29 & 12.9 & 18 & 8 & 13 & 5.8 \\
\hline U.A & 50 & 3.7 & 28 & 56 & 14 & 28 & 7 & 14 & 1 & 2 \\
\hline Glu & 225 & 16.6 & 177 & 78.7 & 16 & 7 & 23 & 10 & 9 & 4 \\
\hline Asp & 175 & 12.9 & 133 & 76 & 29 & 16.6 & 9 & 5 & 5 & 3 \\
\hline Trp & 125 & 9.2 & 84 & 67 & 8 & 6 & 24 & 19 & 9 & 7 \\
\hline Tyr & 50 & 3.7 & 33 & 66 & 6 & 12 & 9 & 18 & 2 & 4 \\
\hline Cys & 75 & 5.5 & 45 & 60 & 12 & 16 & 16 & 21 & 7 & 9 \\
\hline Total No of mutants & 1356 & & 965 & & 146 & & 186 & & 59 & \\
\hline \multirow[t]{3}{*}{ N-source } & \multicolumn{10}{|c|}{ Phx Treatment } \\
\hline & Tota & ants & No o & & No & & No o & & No & \\
\hline & No & $\%$ & No & $\%$ & No & $\%$ & No & $\%$ & No & $\%$ \\
\hline Arg & 200 & 15.6 & 98 & 49 & 82 & 41 & 13 & 6.5 & 7 & 3.5 \\
\hline His & 300 & 23.4 & 183 & 61 & 96 & 32 & 15 & 5 & 6 & 2 \\
\hline Lys & 50 & 3.9 & 42 & 84 & 6 & 12 & 1 & 2 & 1 & 2 \\
\hline Pro & 200 & 15.6 & 124 & 62 & 64 & 32 & 6 & 3 & 6 & 3 \\
\hline U.A & 25 & 2 & 15 & 60 & 8 & 32 & 1 & 4 & 1 & 4 \\
\hline Glu & 200 & 15.6 & 128 & 64 & 56 & 28 & 8 & 4 & 8 & 4 \\
\hline Asp & 200 & 15.6 & 132 & 66 & 60 & 30 & 4 & 2 & 4 & 2 \\
\hline Trp & 50 & 3.9 & 30 & 60 & 17 & 34 & 2 & 4 & 1 & 2 \\
\hline Tyr & 50 & 3.9 & 31 & 62 & 16 & 32 & 2 & 4 & 1 & 2 \\
\hline Cys & - & - & - & - & - & - & - & - & - & - \\
\hline Total No of mutants & 1283 & & 783 & & 413 & & 52 & & 35 & \\
\hline N-source & & & & & eatme & & & & & \\
\hline & Tota & ants & No o & & No & & No o & & No & \\
\hline & No & $\%$ & No & $\%$ & No & $\%$ & No & $\%$ & No & $\%$ \\
\hline Arg & 250 & 19.5 & 199 & 79.6 & 36 & 14.4 & 19 & 7.6 & - & - \\
\hline His & 300 & 23.4 & 256 & 85 & 27 & 9 & 15 & 5 & - & - \\
\hline Lys & 100 & 7.8 & 88 & 88 & 8 & 8 & 4 & 4 & - & - \\
\hline Pro & 350 & 27.3 & 325 & 93 & 18 & 5 & 7 & 2 & - & - \\
\hline U.A & 25 & 2 & 21 & 84 & 3 & 12 & 1 & 4 & - & - \\
\hline Glu & 300 & 23.4 & 264 & 88 & 23 & 8 & 12 & 4 & - & - \\
\hline Asp & 300 & 23.4 & 270 & 90 & 21 & 7 & 7 & 2 & - & - \\
\hline Trp & 100 & 7.8 & 76 & 76 & 20 & 20 & 4 & 4 & - & - \\
\hline Tyr & 50 & 3.4 & 42 & 84 & 6 & 12 & 2 & 4 & - & - \\
\hline Cys & - & - & - & - & - & - & - & - & - & - \\
\hline Total No of mutants & 1775 & & 1543 & & 159 & & 73 & & - & \\
\hline
\end{tabular}

Mutant strains were selected at two temperature regimes $\left(25^{\circ} \mathrm{C}\right.$ and $\left.37^{\circ} \mathrm{C}\right)$ on glucose supplemented minimal medium containing potassium chlorate $(600$ $\mathrm{mM})$ and a sole N-source $(10 \mathrm{mM})$. ${ }^{\text {a }}$ Arg denotes Arginine; His: Histidine; Lys:Lysine; Pro: Proline; U.A: Uric acid; Glu: Glutamic acid; Asp: Aspartic acid; Trp: Tryptophane, Cys: Cysteine and Tyr: Tyrosine. Total number of screened colonies from mutagenesis plates was 3600 ; 1500 ; 1900 and 1900 for spontaneous; DEO; Phx and UV treatment respectively. Total number of confirmed resistant mutants was 1725 ; 1356 ; 1283 and 1775 for spontaneous, DEO, Phx and UV treatments, respectively. 
Effect of applied Treatments on Proportions of Bromate

\section{Resistant Mutants}

Results presented in Table 2 indicate that 976 mutant strains from a total of 1530 (i.e. 63.8\%) screened colonies were isolated on the bases of bromate resistance $(250 \mathrm{mM})$, after four mutagenic treatments (i.e. spontaneous; DEO; Phx and UV treatment). However, the obtained mutants' yield after spontaneous, DEO, Phx and UV treatments were 7.5\%, 76.8\%, $85.6 \%$ and $88 \%$, respectively. The selected mutants were found to represent two phenotypic classes. The first, showed high resistance to bromate but complete sensitivity to chlorate (RS-type) and these were designated brn mutant strains (i.e. bromated resistant nitrate utilizing). The second type of mutants showed high resistance to both selective agents (i.e. bromate and chlorate; RR-type) and designated cbrn strains (chlorate and bromated resistant nitrate utilizing). The brn mutant strains were found to constitute $93.3 \%$ of the total confirmed mutants, whereas cbrn strains have constituted just $6.76 \%$. However, the highest percentages of RS mutants (i.e. $58.6 \%$ and $48 \%$; expressed as percentages from the total confirmed RS strains) were obtained with UA after spontaneous and Phx treatments, whereas Trp has generated $29 \%$ and $42 \%$ of Rs strains after UV and DEO treatments, respectively (Table 2). Results of multivariate ANOVA indicate that the selection temperature, the used $N$-source with the treatments and the interaction between both factors have significantly influenced the ratios of mutants generated after spontaneous, DEO, Phx and UV treatments. Consequently, results presented in Table 3 indicate that the calculated $F$ values for strains with the RS and the RR phenotypes were significantly higher than the tabulated $F$-values in all tested treatments. Results indicate that three (UA, Pro, and Trp) out of ten tested $N$-sources have served effectively as sole sources of nitrogen with all treatments. Uric acid (UA) was serving at $25^{\circ} \mathrm{C}$ rather than $37^{\circ} \mathrm{C}$ as sole $N$-source with all treatments except with Phx treatment, where the selection of mutants was successful at both temperatures $\left(25^{\circ} \mathrm{C}\right.$ and $\left.37^{\circ} \mathrm{C}\right)$. The generated mutants' yields with UA were $60 \%, 39 \%, 50 \%$ and $28 \%$ after spontaneous, DEO, Phx and UV treatments, respectively (Table 2). The amino acid Pro was serving as sole $\mathrm{N}$-source for mutants selection at $25^{\circ} \mathrm{C}$ with spontaneous and DEO treatments, whereas, with Phx and UV treatments the selection was performed at both temperatures $\left(25^{\circ} \mathrm{C}\right.$ and $\left.37^{\circ} \mathrm{C}\right)$ using the same amino acid (Pro). However, when Trp was used with the four tested mutagenic treatments the selection of mutants was successful at both selection temperatures. Furthermore, the amino acids Arg, Glu and His were not effectively acting as sole $N$-sources for the isolation of mutants at any selection temperature after spontaneous treatment. In contrast, all mentioned amino acids were effectively serving as sole $N$-sources at $37^{\circ} \mathrm{C}$ with the UV treatment. Moreover, mutant strains with the RR phenotype (i.e. cbrn strains) were only selected at $25^{\circ} \mathrm{C}$ in all treatments tested (except $\mathrm{Phx}$; mutants were obtained at both selection temperatures) when either Pro or UA was used. However, the proportions of obtained mutants (i.e. with the RR phenotypes) from the total confirmed RR mutant strains were in the range of $0.0 \%$ to 100 $\% ; 47 \%$ to $53 \%$ and $46 \%$ to $54 \%$ after spontaneous, DEO and UV treatments, respectively. The mutants' yields obtained with UA and Pro after $\mathrm{Phx}$ treatment were $22.2 \%$ and $77.8 \%$, respectively (Table 2). Results of multivariate ANCOVA (Covariance) indicate that the chemical (DEO and Phx) and physical (UV) treatments as compared to spontaneous treatment have significantly influenced the ratios of generated bromate mutants (i.e. RS and RR types), where the calculated $F$-values were higher than the tabulated values (Table 4). However, the selection temperature had significantly influenced the effect of DEO treatment on mutants' ratios, where the calculated $F$-values i.e. 54.56 and 15.24 for RS and RR mutant types, respectively were higher than the tabulated $F$-value (4.17) at $d f 1$ and $d f 29$ (Table 4). Moreover, the effect of Phx treatment was greatly influenced by the $N$-source used. The obtained $F$-values for RS and RR strains were 12.11 and 4.84, respectively, whereas, the tabulated $F$-value was 2.69. The proportion of mutant strains with the Rs phenotype only was significantly influenced by selection temperature, where the obtained $F$-value was 27.26 as compared to 4.17 for the tabulated value (Table 4). The effect of UV treatment was 
highly influenced by the $N$-source used, where the calculated $F$-value i.e. 8.08 and 8.79 for RS and RR phenotypes, respectively were higher than the tabulated $F$-value (2.49) at $d f 5$ and $d f 35$ (Table 4). However, the selection temperature showed no significant influence on the treatment action, where the calculated $F$-value was less than the tabulated value (Table 4).

Table 2. Numbers and percentages of confirmed bromate $(250 \mathrm{mM})$ resistant Aspergillus niger mutant classes generated after spontaneous and induced mutagenic treatments.

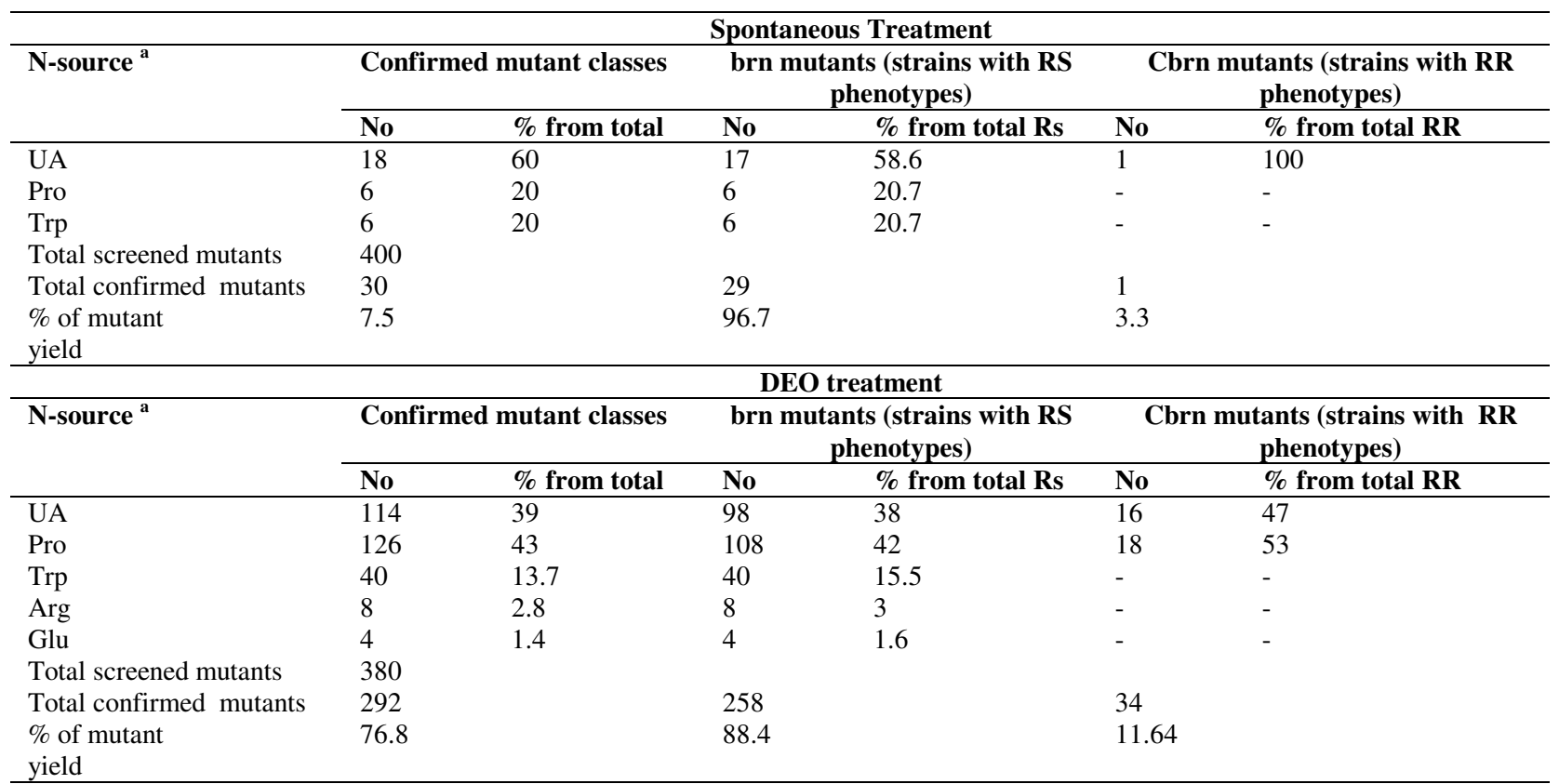
yield

\begin{tabular}{|c|c|c|c|c|c|c|}
\hline \multirow{3}{*}{ N-source ${ }^{\text {a }}$} & \multicolumn{4}{|c|}{ Phx treatment } & \multirow{2}{*}{\multicolumn{2}{|c|}{$\begin{array}{c}\text { Cbrn mutants (strains with } \mathrm{RR} \\
\text { phenotypes) }\end{array}$}} \\
\hline & \multicolumn{2}{|c|}{ Confirmed mutant classes } & \multicolumn{2}{|c|}{$\begin{array}{c}\text { brn mutants (strains with RS } \\
\text { phenotypes) }\end{array}$} & & \\
\hline & No & \% from total & No & $\%$ from total $\mathrm{Rs}$ & No & $\%$ from total $\mathbf{R R}$ \\
\hline UA & 108 & 50 & 94 & 48 & 14 & 77.8 \\
\hline Pro & 42 & 19.6 & 38 & 19.4 & 4 & 22.2 \\
\hline Trp & 34 & 15.9 & 34 & 17 & - & - \\
\hline Arg & - & - & - & - & - & - \\
\hline Glu & 6 & 2.8 & 6 & 3 & - & - \\
\hline His & 24 & 11 & 24 & 12 & - & - \\
\hline Total screened mutants & 250 & & & & & \\
\hline Total confirmed mutants & 214 & & 196 & & 18 & \\
\hline $\begin{array}{l}\% \text { of mutant } \\
\text { yield }\end{array}$ & 85.6 & & 91.6 & & 8.4 & \\
\hline
\end{tabular}
yield

\begin{tabular}{|c|c|c|c|c|c|c|}
\hline \multirow{3}{*}{ N-source ${ }^{a}$} & \multicolumn{4}{|c|}{ UV treatment } & \multirow{2}{*}{\multicolumn{2}{|c|}{$\begin{array}{c}\text { Cbrn mutants (strains with RR } \\
\text { phenotypes) }\end{array}$}} \\
\hline & \multicolumn{2}{|c|}{ Confirmed mutant classes } & \multicolumn{2}{|c|}{$\begin{array}{c}\text { brn mutants (strains with RS } \\
\text { phenotypes) }\end{array}$} & & \\
\hline & No & $\%$ from total & No & \% from total Rs & No & \% from total RR \\
\hline UA & 124 & 28 & 118 & 27.6 & 6 & 46 \\
\hline Pro & 118 & 27 & 111 & 26 & 7 & 54 \\
\hline $\operatorname{Trp}$ & 124 & 28 & 124 & 29 & - & - \\
\hline Arg & 18 & 4 & 18 & 4.2 & - & - \\
\hline Glu & 50 & 11.4 & 50 & 12 & - & - \\
\hline His & 6 & 1.4 & 6 & 1.4 & - & - \\
\hline Total screened mutants & 500 & & & & & \\
\hline Total confirmed mutants & 440 & & 427 & & 13 & \\
\hline$\%$ of mutant yield & 88 & & 97 & & 3 & \\
\hline
\end{tabular}

Mutant strains were selected at two temperature regimes $\left(25^{\circ} \mathrm{C}\right.$ and $\left.37^{\circ} \mathrm{C}\right)$ on glucose supplemented minimal medium containing potassium bromate $(250 \mathrm{mM})$ and a sole N-source $(10 \mathrm{mM}) .{ }^{\mathrm{a}}$ U.A: denotes Uric acid; Pro: Proline; Trp: Tryptophane; Arg Arginine; His: Histidine; Glu: Glutamic acid. ${ }^{\mathrm{b}} \mathrm{RS}$ denotes bromate resistant but chlorate sensitive strain. ${ }^{\mathrm{c}} \mathrm{RR}$ denotes bromate resistant and chlorate resistant strain. 
Table 3. Multivariate ANOVA test for the influence of temperature and $N$-source on treatments` efficiency in obtaining bromate mutants.

\begin{tabular}{|c|c|c|c|c|}
\hline Source & Dependent Variable & F-value & F-critical & $\mathrm{df}$ \\
\hline \multirow[t]{2}{*}{ Spont/N-source } & RS & 423.0 & 5.14 & 2.0 \\
\hline & $\mathbf{R R}$ & 121.0 & & \\
\hline \multirow[t]{2}{*}{ Temperature } & RS & 1513.0 & 5.99 & 1.0 \\
\hline & $\mathbf{R R}$ & 121.0 & & \\
\hline \multirow[t]{2}{*}{ N-source*Temperature } & RS & 379.0 & 5.14 & 2.0 \\
\hline & $\mathbf{R R}$ & 121.0 & & \\
\hline \multirow[t]{2}{*}{ Error } & RS & & & 6.0 \\
\hline & $\mathbf{R R}$ & & & \\
\hline \multirow[t]{2}{*}{ DEO/N-source } & RS & 466.0 & 3.48 & 4.0 \\
\hline & $\mathbf{R R}$ & 1135.0 & & \\
\hline \multirow[t]{2}{*}{ Temperature } & RS & 5550.0 & 4.96 & 1.0 \\
\hline & $\mathbf{R R}$ & 3025.0 & & \\
\hline \multirow[t]{2}{*}{ N-source*Temperature } & RS & 356 & 3.48 & 4.0 \\
\hline & $\mathbf{R R}$ & 1135 & & \\
\hline \multirow[t]{2}{*}{ Error } & RS & & & 10.0 \\
\hline & $\mathbf{R R}$ & & & \\
\hline \multirow[t]{2}{*}{ Phx/N-source } & RS & 709.0 & 3.48 & 4.0 \\
\hline & $\mathbf{R R}$ & 762.0 & & \\
\hline \multirow[t]{2}{*}{ Temperature } & RS & 3713.0 & 4.96 & 1.0 \\
\hline & $\mathbf{R R}$ & 864.0 & & \\
\hline \multirow[t]{2}{*}{$\mathrm{N}$-source*Temperature } & RS & $\mathbf{7 9 5 . 0}$ & 3.48 & 4.0 \\
\hline & $\mathbf{R R}$ & 357.0 & & \\
\hline \multirow[t]{2}{*}{ Error } & RS & & & 10 \\
\hline & $\mathbf{R R}$ & & & \\
\hline \multirow[t]{2}{*}{ UV/N-source } & RS & 6870.0 & 3.11 & 5.0 \\
\hline & $\mathbf{R R}$ & 781.0 & & \\
\hline \multirow[t]{2}{*}{ Temperature } & RS & 4284.0 & 4.75 & 1.0 \\
\hline & $\mathbf{R} \mathbf{R}$ & 48.0 & & \\
\hline \multirow[t]{2}{*}{ N-source*Temperature } & RS & 13013.0 & 3.11 & 5.0 \\
\hline & $\mathbf{R R}$ & 154.0 & & \\
\hline \multirow[t]{2}{*}{ Error } & RS & & & 12.0 \\
\hline & $\mathbf{R R}$ & & & \\
\hline
\end{tabular}

Table 4. Multivariate ANCOVA for the influence of treatments as compared to spontaneous treatment in generating bromate mutant classes.

\begin{tabular}{|c|c|c|c|c|}
\hline Source & Dependent Variable & F-value & F-critical & $\mathrm{df}$ \\
\hline \multirow{2}{*}{ UV treatment } & RS & 23.9 & 4.15 & 1.0 \\
\hline & $\mathbf{R R}$ & 6.75 & & \\
\hline \multirow[t]{2}{*}{$\mathrm{N}$-source } & RS & 8.08 & 2.49 & 5.0 \\
\hline & $\mathbf{R R}$ & 8.79 & & \\
\hline \multirow[t]{2}{*}{ Temperature } & RS & 0.83 & 4.15 & 1.0 \\
\hline & $\mathbf{R R}$ & 2.79 & & \\
\hline \multirow[t]{2}{*}{ N-source*Temperature } & RS & 7.86 & 2.49 & 5.0 \\
\hline & $\mathbf{R R}$ & 4.60 & & \\
\hline \multirow[t]{2}{*}{ Error } & $\mathbf{R S}$ & & & 35.0 \\
\hline & $\mathbf{R R}$ & & & \\
\hline \multirow[t]{2}{*}{ Phx treatment } & RS & 18.07 & 4.17 & 1.0 \\
\hline & $\mathbf{R R}$ & 8.31 & & \\
\hline \multirow[t]{2}{*}{$\mathrm{N}$-source } & RS & 12.0 & 2.69 & 4.0 \\
\hline & $\mathbf{R R}$ & 4.84 & & \\
\hline \multirow[t]{2}{*}{ Temperature } & $\mathbf{R S}$ & 27.26 & 4.17 & 1.0 \\
\hline & $\mathbf{R R}$ & 3.15 & & \\
\hline \multirow[t]{2}{*}{ N-source*Temperature } & RS & 1.74 & 2.69 & 4.0 \\
\hline & $\mathbf{R R}$ & 1.21 & & \\
\hline \multirow[t]{2}{*}{ Error } & RS & & & 29.0 \\
\hline & $\mathbf{R R}$ & & & \\
\hline \multirow[t]{2}{*}{ DEO treatment } & RS & 5.37 & 4.17 & 1.0 \\
\hline & $\mathbf{R R}$ & 6.77 & & \\
\hline \multirow[t]{2}{*}{$\mathrm{N}$-source } & RS & 12.80 & 2.69 & 4.0 \\
\hline & $\mathbf{R R}$ & 6.03 & & \\
\hline \multirow[t]{2}{*}{ Temperature } & RS & 54.56 & 4.17 & 1.0 \\
\hline & $\mathbf{R R}$ & 15.24 & & \\
\hline \multirow[t]{2}{*}{ N-source*Temperature } & RS & 4.89 & 2.69 & 4.0 \\
\hline & $\mathbf{R R}$ & 6.03 & & \\
\hline \multirow[t]{2}{*}{ Error } & RS & & & 29.0 \\
\hline & $\mathbf{R R}$ & & & \\
\hline
\end{tabular}




\section{DISCUSSION}

The highest yield of chlorate resistant mutants was obtained after UV treatment (93.4\%) this was followed by a 90\% yield obtained with the DEO treatment. Concerning chlorate toxicity it had been previously proposed that chlorate itself is not toxic, but it renders toxic when it is converted (In vivo) to chlorite by the action of the molybdoenzyme nitrate reductase. i..e. chlorate serves as an analogue for nitrate during reduction in bacteria, fungi, algae and higher plants $(10,19)$. However, this might not be the mechanism of action for chlorate, because not all mutants lacking nitrate reductase are chlorate resistant, i.e. both chlorate sensitive and resistant mutants lacking nitrate reductase. A possible explanation for chlorate toxicity is that it mimics nitrate and lead to a shutdown of nitrogen metabolism, as chlorate can not act as nitrogen source (11). In addition, an important feature should be met to demonstrate that chlorate and nitrate share a common transport system is that they should each competitively inhibit the uptake of the other ion (19). Concerning the Specificity and effectiveness of employed mutagenic treatments in inducing forward mutations in Aspergillus niger at several gene loci, the niaD mutants were obtained with the highest percentage (73.97\% of the total generated mutants) with all mutagenic treatments whatever, the used $N$-source or the selection temperature. However, cnx mutants have ranked the second, in terms of total mutants yield (17.8\%) obtained with all treatments (Table 3). Furthermore, Phx treatment as compared with other treatments has generated the highest cnx ratio $(32 \%)$. The high relative frequency of this mutant type may suggest that the niaD gene contains one or more mutational hot spots that became easily altered with reduced capacity for DNA repairing. These findings disagreed with that obtained previously by Cove $(9,10)$ which indicated that $\operatorname{cnx}$ genes were more susceptible to mutations than niaD gene. However, our results agreed with the findings of Kanan et al. (18). Moreover, it seems likely that $n r t$ (generated with a $6.4 \%$ yield of the total mutants) and nirA (obtained with a yield of 1.9\%) genes were relatively less prone to mutations whatever the applied treatment, the $N$-source or the selection temperature used and this agreed with the findings of Cove (9) and also with that of Kanan et al. (18). The success of certain $N$-source in generating high ratio of specific mutants type under specific treatments conditions but not the other, could be related to the type and position of mutation in the altered gene(s) involved in the utilization of different $N$-sources. This kind of alteration (either in the transcriptional factors or in $N$-source utilization genes) could make one nitrogen source unable to be metabolized under certain treatments` conditions but not the others. These suggestions confirm not unexpectedly the previous findings (9, $12,18,20,21)$ which stated that the effective transcription of genes involved in $\mathrm{N}$-sources utilization, the type of $\mathrm{N}$-source used, the selection temperature and the interactions between them had significantly influenced the ratio of selected mutants. The spontaneously generated mutations comprise the ultimate source of natural genetic variation that is seen in populations. The frequency at which spontaneous mutations occur is low, since these are the resultants of low level inherent metabolic errors, or they may actually caused by unknown agents present in the environment (30). The DEO mutagen was preferentially affecting the treated conidiospores more than UV and $\mathrm{Phx}$ treatments, and this confirm the previous findings of Yunes, et. al. (37) stated that DEO was more carcinogenic and mutagenic than the other analogues. The DEO mutagen reacts preferentially with the $\mathrm{N}_{7}$ of guanosine and the $\mathrm{N}_{3}$ of adenine, then induces both mono-adducts and inter-strand cross-links by specific genotoxic pathway in absence of cell death, $(34,37)$. However, the UV-induced thymine dimers cause mutations in two ways. (I) dimers perturb the structure of DNA double helices and interfere with accurate DNA replication. (II) Errors occur during the cellular processes that repair defects in DNA $(30,35)$. Furthermore, previous results revealed that potassium bromate was mutagenic to bacteria, and this activity was mediated by the formation of oxidative damage to DNA, where the reduction of bromate under aerobic and anaerobic conditions was attributed to chemical rather than biological reduction (28). However, as chlorate, bromate was found to act as electron acceptor for bacteria, thus it is likely to be used in 
the same enzymatic reduction (15). This may lead to the suggestion that bromate toxicity arises as a result of mimicking nitrite (being its toxic analogue), so it might alter specific genes responsible for the active uptake of nitrite, which suggests that brn strains (with the RS phenotypes) may specify a nitrite specific system independent from the nitrate transport system specified by $n r t$ gene (with the SR phenotypes). Furthermore, the occurance of $c b r n$ strains with RR phenotypes may specify specific components for a complex bispecific transporter that is responsible for the transport of both nitrate and nitrite. The mutation at the cbrn locus may be influenced by the nature of $n r t$ and brn genes, which suggests overlapping sequence, where the cbrn alteration may arise as a result of double loss mutation in both genes. Furthermore, if the recombinant progeny (i.e. non-parental recombinants) are recovered from out crosses between the wild-type and $n r t$ or brn mutants, this suggests that chlorate and bromate resistant may occur due to a complex locus that co-segregates as a single gene or two tightly linked genes. This locus is independent from the chlorate specific one which is represented by nrt mutants showing complete sensitivity to bromate but high resistance to chlorate (SR-type). In addition, bromate resistance in brn strains that show high resistance to bromate but not to chlorate i.e. RS phenotypes may result from a distinct locus that is independent from the bispecific one (RR-type) or the chlorate specific locus. These suggestions would agree with that of Kanan (17) who stated that results of recombination analysis and biochemical studies on the $A$. nidulans brn and cbrn mutant strains suggest that these strains may specify a nitrite specific and nitrate/nitrite bi-specific transporters, respectively.

\section{CONCLUSIONS}

As a consequence of the double selection for nitrate assimilation defective mutants on chlorate and bromate, new phenotypes (i.e. with RS and RR phenotypes) were observed. This selection system which is based on bromate resistance is considered valuable in terms of applying it in addition to the classical chlorate system as a selective agent for mutants` selection. The isolation of mutant strains (brn mutants) with the RS phenotype, i.e. showing the antagonistic phenotypes of the SR chlorate mutants is also valuable for the characterization of nitrite specific transporters. The most relevant and innovative findings of this research work is the isolation of mutants with the RR phenotypes (i.e. cbrn mutant strains) which are new form of nitrate assimilation defective mutants that could be useful for studying the bispecific nitrate/nitrite transport system. However, $93.3 \%$ of the total isolated bromate resistant mutants were of the brn type (i.e. RS phenotypes), whereas the cbrn mutant strains (RR phenotypes) have constituted just $6.8 \%$. The brn strains were obtained at a percentage of $58.6 \%$ and $48 \%$ of the total RS strains when UA was used as sole $N$ source with the spontaneous and Phx treatments. In addition, Trp has generated $29 \%$ and $42 \%$ of RS strains after UV and DEO treatments, respectively. The chemical treatments (i.e. DEO and Phx) were more efficient in generating cbrn strains where, the obtained percentage was in the range of $8.4 \%$ to $11.6 \%$ of the total bromate strains. Uric acid (UA) and Proline (Pro) were the only $N$-sources that have served effectively for the generation of cbrn mutant strains in all treatments tested. Moreover, the $c b r n$ strains were only selected at $25^{\circ} \mathrm{C}$ with all treatments except Phx treatment which generates RR mutants (in the range of $22 \%$ to $77.8 \%$ ) at both selection temperatures. The obtained results indicate that a mutants' yield of approximately $69 \%$ of the four loci (niaD, cnx, nrt and nirA genes) was obtained on the bases chlorate $(600 \mathrm{mM})$ toxicity, using four mutagenic treatments (spontaneous, DEO, Phx and UV). However, all chlorate resistant mutants were completely sensitive to bromate $(250 \mathrm{mM})$. The highest mutants`yield (93.4\%) was obtained with UV treatment, whereas the least $(47.9 \%)$ was achieved with the spontaneous treatment. The tested selection temperatures did not significantly influenced the ratios of generated mutants. The amino acids Arg, His, Pro, Glu, Asp and Tyr were the best serving $N$-sources for mutants selection, where approximately equal ratios of mutants were obtained at both selection temperatures. However, Lys and Trp did not serve as sole $N$-sources for mutants selection at 
$25^{\circ} \mathrm{C}$ with all treatments except the DEO treatment. In addition, Cys was not the $N$-source of choice for mutants selection at any of the tested temperatures. The niaD mutants have ranked the first among all chlorate resistant mutants in terms of achieved mutant yield (73.97\% of the total mutants), by all tested treatments. However, the UV treatment has generated the highest niaD ratio $(86.9 \%)$, whereas, the least was obtained with Phx treatment. The obtained mutants`yield in $c n x$ genes was $17.8 \%$ of the total mutants generated from all treatments (except DEO treatment). However, a 32\% of the total mutants generated after Phx treatment was of cnx type which was the highest among tested treatments. The obtained $n r t$ mutants`yield was ranked the third among isolated mutant types, where only $6.4 \%$ of the total confirmed mutants were achieved by all treatments (except DEO; generates 13.8\%). The nirA mutant yield was the least obtained (1.9\%) with all treatments. However, DEO treatment was the best to use for the isolation of these types of mutants. In contrast, no single nirA mutant was obtained with any of the ten tested $N$-sources after UV treatment.

\section{ACKNOWLEDEGMENT}

Authors would like to thank Mu'tah University, Jordan for providing the requirements and the suitable environment for this research work. Thanks are also due to Dr. J. R. Kinghorn, University of St. Andrews, Scotland-UK for providing the wild-type strain.

\section{REFERENCES}

1. Adelberg, E.A.; Mandel, M.; Chen, G.C. (1965). Optimal conditions for mutagenesis by N-methyl N-nitro-N- nitrosoguanidine in Escherichia coli K12. Biochem. Biophys. Res. Comm. 18, 788-795.

2. Alderson, T.; hartly, M.J. (1969). Specificity for spontaneous and induced forward mutation at several gene loci in Aspergillus nidulans. Mutat. Res. 8, 255-264.

3. Akintonwa, A.; Awodele, O.; Emeka, P.M.; Osajare, O. (2007). The mutagenic potentials of potassium bromate and some commonly used food additives. Afr. J. Biotechnol. 6 (8), 1004-1006.

4. Appleyard, M.V.C.L.; Sloan, J.; Kanan, G.J.M.; Heck, I.S.; Kinghorn,
J.R.; Unkles, S.E. (1998). The Aspergillus nidulans cnxF and its involvement in molybdenum biosynthesis. J. Biol. Chem. 273 (24), 14869-14876.

5. Bos, C.J. (1987). Induction and isolation of mutants in fungi at low mutagen doses. Curr. Genet. 12, 471- 474.

6. Burger, G.; Tilburn, J.; Scazzocchio, C. (1991). Molecular cloning and functional characterization of the pathway-specific regulatory gene nirA, which controls nitrate assimilation in Aspergillus nidulans. Mol. Cell. Biol. 11 (2), 795-802.

7. Clutterbuck, A.J. (1974). Aspergillus nidulans. In: King, R.C. (eds). Vol. I. Handbook of genetics Bacteria, bacteriophages and fungi. New York, London, Plenum Press, p. 447-510.

8. Coral, G.; Arikan, B.; Onald, M.N.; Guvenmez, H. (2002). Some properties of crude carboxymethyl cellulase of Aspergillus niger Z10 wild-type strain. Turk. J. Biol. 26, 209-213.

9. Cove, D.J. (1976a). Chlorate toxicity in Aspergillus nidulans: The selection and characterization of chlorate resistant mutants. Hered. 36 (2), 191-203.

10. Cove, D.J. (1976b). Chlorate toxicity in Aspergillus nidulans: Studies of mutants altered in nitrate assimilation. Mol. Genet. Genom. 146, 147-159.

11. Cove, D.J. (1979). Genetic studies of nitrate assimilation in Aspergillus nidulans. Biol. Rev. 54 (3), 291-327.

12. Caddick, M.X.; Arst, H.N.; Taylor, L.H.; Johnson, R.I.; Brownlee, A.G. (1986). Cloning of the regulatory gene areA mediating nitrogen metabolite repression in Aspergillus nidulans. EMBO. 5 (5), 1087-1090.

13. Debets, A.J.M.; Swart, K.; Bos, C. J. (1990). Genetic analysis of Aspergillus niger: Isolation of chlorate resistance mutants, their use in mitotic mapping and evidence for an eighth linkage group. Mol. Gene. Genom. 221, 453-458.

14. Harrington-Brock, K.; Collard, D.D.; Chen, T. (2003). Bromate induces loss of heterozygosity in the Thymidine kinase gene of L5178Y/TK+/-3.7.2C mouse lymphoma cells. Mutat. Res. 537, 21-28.

15. Hijnen, W.A.M.; Voogt, R.; Veenendaal, H.R.; Van der Jagt, H.; Van der Koou, D. (1995). Bromate reduction by denitrifying bacteria. Appl. Environ. Microbiol. 61 (1), 239-344.

16. Ilczuk, Z. (1973). Synthesis of pectolytic enzymes by UV-induced mutants of Aspergillus niger. Acta Microbiol. Pol. 5 (22), 95-101.

17. Kanan, G.J.M. (2002). Bromate toxicity in Aspergillus nidulans: Isolation and growth characterization of two novel putative nitrate transport encoding genes through mutants selection and subsequent meiotic recombination analysis of brn mutants. Mu'tah Lil-Buhuth wadDirasat. 17 (2), 71-100.

18. Kanan, G.J.M.; Qaseer, H.A.; El-Qisairi, A.K.; Zaghal, M.H.; Al-Najar, H.A. (2002). Chemically induced mutagenesis in Aspergillus nidulans using cis-[$\left[\mathrm{Pd}(\mathrm{biq}) \mathrm{Cl}_{2}\right]$ as compared with NTG and spontaneous mutations. Mu'tah Lil-Buhuth wad-Dirasat. 17 (2), 101-132.

19. Kosola, K.R.; Bloom, A.J. (1996). Chlorate as a transport analog for nitrate absorption by roots of tomato. Plant Physiol. 110, 1293-1299.

20. Lenouvel, F.; Fraissinet-Tachet, L.; Van de Vandervoort, P.J.I.; Visser, J. 
(2001). Isolation of UV-induced mutations in the areA nitrogen regulatory gene of Aspergillus niger, and construction of a disruption mutant. Mol. Genet. Genom. 266, 42-47.

21. MacCabe, A.P.; Vanhanen, S.; Gelpke, M.D.S.; Van de Vondervoort, P.J.I.; Arst, H.N.; Visser, J. (1998). Identification, cloning and sequence of the Aspergillus niger areA wide domain regulatory gene controlling nitrogen utilization. Biochem. Biophys. Acta. 1396, 163-168.

22. Mackintosh, M.E.; Pritchard, R.H. (1963). The production and replica plating of micro colonies of Aspergillus nidulans. Genet. Res. 4, 321-322.

23. Moore, M.M.; Chen, T. (2006). Mutagenicity of bromate: Implications for cancer risk assessment. Toxicol. 221, 190-196.

24. Oni, O.A.; Oladele, O.I.; Inedia, O.F. (2005). Consumer willingness to pay for safety labels in Nigeria: A case study of potassium bromate in bread. J. Cenet. Europe. Agri. 6 (3), 381-388.

25. Picada, J.N.; Khromov-Borisov, N.N.; Henriques, J.A.P. (1999). Deletogenic activity of 1,2,7,8-diepoxyoctane in Salmonella typhimurium tester strain TA102. Mutat. Res. 437, 165-173.

26. Pungartnik, C.; Picada, J.; Brendel, M.; Henriques, J.A.P. (2002). Further phenotypic characterization of Pso mutants of Saccharomyces crevisiae with respect to DNA repair and response to oxidative stress. Genet. Mol. Res. 1 (1), 79-89.

27. Punt, P.J.; Strauss, J.; Smith, R.; Kinghorn, J. R.; Van Den Hondel, C.A.M.J.J.; Scazzocchio, C. (1995). The intergenic region between the divergently transcriped niiA and niaD genes of Aspergillus nidulans contains multipe NirA binding sites which act bidirectionally. Mol. Cell. Biol. 15 (10), 5688-5699.

28. Rodgers, G.A. (1980). Evolution of potential substrates to monitor respiratory nitrate reductase activity in soil. J. Soil Sci. 31, 387-395.

29. Ruana, J.; Urbe, I.; Borrull, F. (1993). Determination of phenols at the $\mathrm{ng} / \mathrm{l}$ level in drinking and river waters by liquid chromatography with UV and electrochemical detection. J. Chrom. 655 (2), 217-226.

30. Snustad, D.P.; Simmons, M.J. (2000). Priciples of Genetics. John Wiley and Sons, Inc, USA.

31. Unkles, S.E.; Campbell, E.I.; Punt, P.J.; Hawker, K.L.; Contreras, R.; Van den Hondel, C.; Kinghorn, J.R. (1992). The Aspergillus niger niaD gene encoding nitrate reductase: upstream nucleotide and amino acid sequence comparisons. Genet. 111, 149-155.

32. Unkles, S.E.; Smith, J.; Kanan, G.J.M.M.; Miller, L.J.; Heck, I.S.; Boxer, D.H.; Kinghorn, J.R. (1997). The Aspergillus nidulans cnxABC locus is a single gene encoding two catalytic domains required for synthesis of precursor $\mathrm{Z}$, an intermediate in molybdenum cofactor biosynthesis. $J$. Biol. Chem. 272 (45), 28381-28390.

33. Verdoes, J.C.; Van Diepeningen, A.D.; Punt, P.J.; Debets, A.J.M.; Stouthamer, A.H.; Van den Hondel, C. (1994). Evaluation of molecular and genetic approaches to generate glucoamylase overproducing strains of Aspergillus niger. J. Biotechnol. 36, 65-175.

34. Vock, E.H.; Lutz, W.K.;Ilinskaya, O.; Vamvakas, S. (1999). Discrimination between genotoxicity and cytotoxicity for the induction of DNA double-strand breaks in cells treated with aldehydes and diepoxides. Mutat. Res. 441, 85-93.

35. Wolstenholme, G.E.W.; O'connor, M. (1969). Mutation as Cellular Process. Churchill Ltd, London.

36. Yamaguchi, T.; Wei, M.; Hagihara, N.; Omori, M.; Wanibuchi, H.; Fukushima, S. (2008). Lack of mutagenic and toxic effects of low dose potassium bromate on kidneys in the big blue rat. Mutat. Res. 652 (1), 111.

37. Yunes, M.J.; Charnecki, S.E.; Marden, J.J.; Millard, J.T. (1996). 1,2,5,6Diepoxyhexane and 1,2,7,8-Diepoxyoctane cross-link duplex DNA at 5'GNC sequences. Chem. Res. Toxicol. 9, 994-1000. 